University of Nebraska - Lincoln

DigitalCommons@University of Nebraska - Lincoln

Fall 2010

Introduction to Special Issue: Public Argument/Digital Media

Damien S. Pfister

University of Nebraska-Lincoln, dpfister2@unl.edu

Follow this and additional works at: https://digitalcommons.unl.edu/commstudiespapers

Part of the Communication Technology and New Media Commons, and the Speech and Rhetorical

Studies Commons

Pfister, Damien S., "Introduction to Special Issue: Public Argument/Digital Media" (2010). Papers in Communication Studies. 6.

https://digitalcommons.unl.edu/commstudiespapers/6

This Article is brought to you for free and open access by the Communication Studies, Department of at DigitalCommons@University of Nebraska - Lincoln. It has been accepted for inclusion in Papers in Communication Studies by an authorized administrator of DigitalCommons@University of Nebraska - Lincoln. 


\title{
ARGUMENTATION AND ADVOCACY
}

\section{INTRODUCTION TO SPECIAL ISSUE: PUBLIC ARGUMENT/DIGITAL MEDIA}

\author{
Damien Smith Pfister, Guest Editor
}

\begin{abstract}
This introductory essay to the special issue of Argumentation and Advocacy on Public Argument/Digital Media makes the case for a sustained interrogation of digitally-networked argumentation practices. To complement current scholarship on how new forms of digital mediation produce group polarization and truthiness, I suggest that argumentation scholars look at digital media as a rich source for the production and criticism of argument. Each of the essays in the special issue is then introduced by examining five cross-cutting themes that argumentation scholars may consider when examining how digital media produce networked argument practices: interactivity, instantaneity, scale, archiving, and search. Key Words: digital media, networked argument practices, polarization, truthiness
\end{abstract}

What is the fate of public argument in an era of digital media? It is all too easy to follow Stephen Colbert's lead and simply suggest that "truthiness" reigns given that public argument often appears dominated by gut reactions, under-scrutinized evidence, lazy claim comparisons, and unjustified warrants. Truthiness is found in the politician who ignores evidence in favor of ideological predispositions, in the undergraduate who quotes from satirical news websites without recognizing the satire, and in the citizen who follows only one talking head on the nightly cable news networks.

The rise of truthiness is inextricably connected to the proliferation of media. No longer does the newspaper or broadcast television program set a common agenda for the nation, with ostensibly reliable opinion leaders filtering through information before publication of the "news" (Bennett and Manheim, 2006). Instead, as Cass Sunstein (2002, 2007, 2009) has repeatedly warned, citizens living in a time of information abundance set up filters to winnow down the data that endlessly streams toward their eyes and ears. These filters often cohere with their already established viewpoints, creating echo chambers of the like-minded that polarize over time. People literally live in different-to coin a term-factiverses. Arguers can find support for almost any argument by searching the vast intercast of the internet. It is a safe bet that if you can think it, it has been published on some digital network. A common, and warranted, impulse for many argumentation scholars is to bemoan this phenomenon

Damien Smith Pfuster, Department of Communication Studies, University of Nebraska-Lincoln. I would like to thank Catherine Palczewski and John Fritch for the opportunity to guest edit this special issue of Argumentation and Advocacy and the host of reviewers who provided thoughtful and incisive commentary on each essay. I would also extend a hearty thank you to the authors for charitable interpretations of criticism, diligent revisions, and timely responses. Correspondence concerning this article should be addressed to Damien Smith Pfister, Department of Communication Studies, University of Nebraska-Lincoln, 439 Oldfather Hall, Lincoln, Nebraska,68588. E-mail: dpfister2@unl.edu 
because it undermines many of the assumptions of liberal public argument that have constituted the intellectual infrastructure of modernity. Argumentative norms, like listening to both sides of an issue before forming an opinion, making transparent the moves from evidence to warrants and claims, and maintaining civil relations with co-arguers, often do not appear to prevail in environments mediated by digital technologies.

Another story might be told, however, that would shift the frame from a declinist narrative of public argument to a more hopeful one. Such a competing story would emphasize not the decline of the modernist norms of argumentation, but the spread and even sophistication of argument practices in a networked era. Much of what happens in the blogosphere, on social networking sites, through microblogging, via video-sharing sites, and by means of discussion forums is the production and criticism of argumentation. Though citizens have been producing and criticizing argument outside the purview of print and electronic media for centuries, networked digital media provide new opportunities for them to do so with an unprecedented degree of publicity and interconnectivity. The face-to-face conversation that used to occur over the backyard fence is now supplemented by many-to-many contexts of communication; making these once limited-circulation arguments public through digital media now invites scores of interlocutors to weigh in. Disagreements that used to be mediated orally can now be conducted hypertextually, with links to premises and evidence embedded in the text of the argument itself. These emergent networked argument practices deserve further critical scrutiny and theorization as scholars grapple with how new forms of mediation alter the norms and conduct of argumentation.

As the fora for public argument have expanded, the language of argumentation has-at least informally-permeated a wider variety of social contexts. It is no longer uncommon to see requests for evidence on threaded discussions, criticisms of argument structures on blogs, or exchanges of perspective in comments sections. Such diffusion provides an enormous opening for scholars of public argument to describe, analyze, and critique argumentation practices that occur in digitally networked environments. In some cases, traditional argumentation tools can help us interpret public argument mediated through new digital technologies, but in other cases scholars will be called upon to articulate new concepts, theories, and heuristics to better analyze digitally networked arguments. This special issue of Argumentation and Advocacy continues the conversation about the relationship between public argument and digital media in ways that open up new vistas for research in this area.

Scholars exploring how digital media have changed patterns of communication and culture have identified five key features of internetworked interaction: interactivity, instantaneity, scale, archiving, and search. The much-ballyhooed interactivity of the internet provides greater feedback loops and avenues for co-creation of discourse (Warnick, 2007). Messages, which just a shade over a century ago would have taken weeks or months to go coast-to-coast in the United States, can now speed around the globe instantaneously. By eliminating the turn-taking required in oral discourse to hear each other and magnifying the asynchronous elements of print-based deliberation, the internet has greatly increased the scale of communication; it is the first truly many-to-many forum for communication. Unlike speech (which dissipates upon utterance), or print media (which must be stored in centralized depositories like libraries), or electronic broadcast media (which until recently had been difficult to collect), the internet is a vast archive of information made public. This archive provides a rich resource for the invention of argumentation, but can only be made sense of with the search capabilities that now filter through the dense information flows that increasingly connect fragments of discourse. The essays collected in this special issue, competitively 
selected after a blind review process, each showcase how these five features are changing the practice of argumentation and advocacy.

Each of the essays illustrates a different dimension of interactivity. E. Johanna Hartelius's “Leave a Message of Hope or Tribute': Digital Memorializing as Public Deliberation" examines how the National September 11 Memorial and Museum's website transforms private meditations on national tragedy into public resources for invention in public argument. Hartelius detects a significant change in how collaborative digital environments change the way that citizens imagine their relations with each other and how they remember history. Marcin Lewiński, in "Collective Argumentative Criticism in Informal Online Discussion Forums," theorizes how the interactivity offered by discussion forums yields two novel patterns of argument. In horizontal criticism, interlocutors expand the topoi to be considered on any one argument; in vertical criticism, arguers deepen a single line of argument. Both variants have roots in prior patterns of argumentation but are receiving unique wrinkles in networked sites of argumentative engagement. Aaron Hess charts the shift from a mass-mediated era to a networked one in "Democracy through the Polarized Lens of the Camcorder: Argumentation and Vernacular Spectacle on YouTube in the 2008 Election." Hess locates how citizens in the new, participatory mediascape create "vernacular spectacles" by making videos of what he calls "idiot opponent montages" of political opponents at political rallies. Circulating to millions on YouTube, such polarizing videos might, Hess warns, ultimately stunt participation by further pushing groups to extremes. Finally, Christina Smith and Kelly MacDonald demonstrate how the agenda-setting functions of the mass media, along with carefully crafted institutional deliberation, have been disrupted in "The Arizona 9/11 Memorial: A Case Study in Public Dissent and Argumentation through Blogs." In this case study, Smith and MacDonald identify how the previously pyramidal flow of information through the mass media has been supplanted by a networked architecture of self-reinforcing public argument. In this case, conservative bloggers whipped up a firestorm over the Arizona 9/11 Memorial, ultimately pressuring decision-makers to revise the design that had been agreed upon through a years-long process of consensus-based deliberation.

That digital media have sped up the rate and scale of public argument is also demonstrated in this collection of essays. For Smith and MacDonald, the rapidity of the conservative blogswarm (itself a term that connotes instantaneity) was difficult for defenders of the Memorial to cope with, especially as their criticisms were re-mediated and amplified to broader audiences through the traditional broadcast press. In another sign of instantaneity, the chair of the commission that designed the Arizona 9/11 Memorial utilized the comments section extending off an article in the digital version of a local paper to defend the project. For Hess, too, the comments that flow from idiot opponent montage videos illustrate the accelerated processes of reaction in contemporary digital public culture. Lewiński identifies how the internet has scaled up public discourse by noting that it hosts what can only be called a polylogue, which hints at the greater circulation of public argument in an internetworked era. For Lewinski, this expansion of the collective repertoire of argumentation may encourage participation in public deliberation. Hartelius, on the other hand, is more suspicious of how the processes of publicity may simultaneously discipline interlocutors.

The internet as a searchable archive is another thread that wends through each essay. Hartelius excavates how individual ruminations on $9 / 11$ constitute an ever-morphing archive of private thoughts converted to publicly available observations. Rather than the seeming stability offered by material memorials of granite and steel, the digital memorial is 
always in flux as individuals renegotiate their understanding of a national tragedy. The bloggers whom Smith and MacDonald highlight are themselves engaged in the processes of constructing an archive of arguments in a related public controversy over brick and mortar memorials. Of course, once archives exceed a certain threshold, they are only as useful as the methods used to search them. Lewinski's participants in collective criticism search for evidence to support their claims across the whole breadth of the internetworked archive (with varying degrees of success). Similarly, Hess's digital videographers compile splices of extreme partisans at political assemblies through the search capacities offered on video sharing sites in order to assemble their idiot opponent montages.

Although these five themes unify the essays in this special issue and extend contemporary theorizing on the implications of digital media for public argument, there are other unifying themes: the increasing prominence of vernacular expression (Hartelius, Hess, and Lewiński), the persistence of $9 / 11$ memorializing in sparking public controversy (Hartelius, Smith \& MacDonald), and the reconfiguration of electoral politics (Hess, Lewiński, and Smith \& MacDonald). These additional three themes suggest that digital media are so connected to particular historical contexts that they cannot be theorized outside of parallel evolutions in our increasingly internetworked public culture. These essays are exemplars of the kind of work that can be done to enhance our understanding of how new forms of media change patterns of public argument and deliberation.

This special issue also requires one additional level of introduction. As the editors and authors worked through editing, it became increasingly clear that existing style manuals create unwieldy citation formats. Thus, you may notice some innovative formats are used. For example, in many cases, paragraph numbers for online sources are not included because the format of the source did not lend itself to paragraphs or the site was ephemeral. In other instances, individual citations are not provided for a series of blog posts; instead, one overarching url is provided for the exchange. In all cases, the goal was to provide sufficient documentation so that interested readers could track the information while not overwhelming the essay with overly long parenthetical citations.

\section{REFERENCES}

Bennett, L., \& Manheim, J. (2006). The one-step flow of communication. The Annals of the American Academy of Political and Social Science, 608, 213-32.

Sunstein, C. (2002). Republic.com. Princeton, NJ: University of Princeton Press. (2007). Republic.com 2.0. Princeton, NJ: University of Princeton Press. (2009). Going to extremes: How like minds unite and divide. Oxford: Oxford University Press.

Warnick, B. (2007). Rhetoric online: Persuasion and politics on the World Wide Web. New York: Peter Lang. 